\title{
Preservation of Permeability Barrier Ontogenesis in the Intrauterine Growth-Retarded Fetal Rat
}

\author{
MARY L. WILLIAMS, MICHELLE ASZTERBAUM. GOPINATHAN K. MENON. \\ ARTHUR H. MOSER, KENNETH R. FEINGOLD. AND STEVEN B. HOATH

\begin{abstract}
Departments of Dermatology [M.L.W., M.A., G.K.M.], Pediatrics [M.L.W.], and Medicine [A.H.M., K.R.F.], of Pediatrics [S.B.H.]. University of Cincinnati, Cincinnati, Ohio 45267-0541
\end{abstract} \\ University of California San Francisco, and Dermatology [M.L.W., M.A., G.K.M.] and Medical [A.H.M., K.R.F.] \\ Services, Department of Veterans Affairs Medical Center, San Francisco, California 94121; and the Department
}

\begin{abstract}
The epidermal permeability barrier is provided by intercellular lipids forming multiple membrane bilayers in the stratum corneum. In the fetal rat, the barrier to transepidermal water loss forms during the 20th $\mathrm{d}$ of gestation and is accompanied by 1 ) increasing stratum corneum thickness; 2) increasing stratum corneum lipid content, particularly nonpolar ceramide and cholesterol content; and 3) the formation of lamellar unit structures throughout the stratum corneum interstices. In this report. we demonstrate that among pups of $20 \mathrm{~d}$ gestational age increasing barrier competence is correlated with increasing fetal weight. It has been previously demonstrated that fetal rats subjected to intrauterine growth retardation (IUGR) exhibit a thinner stratum corneum and decreased content of differentiation-specific epidermal structural proteins. To determine whether IUGR fetal rats also exhibit immaturity of barrier function and the barrier membrane system, maternal rats underwent unilateral uterine vessel ligation on d 17 or 18 of gestation and IUGR and control littermates were harvested on d 20,21 , or 22 of gestation for determination of transepidermal water loss. Despite significant somatic growth retardation and a thinner stratum corneum, barrier function in IUGR fetal rats did not significantly differ from that in control littermates at any gestational age. In both IUGR and control fetal rat epidermis at $21 \mathrm{~d}$ gestational age, lipids were deposited in a membrane pattern as visualized by nile red fluorescence microscopy and formed lamellar unit membrane structures throughout the stratum corneum intercellular domains as observed by electron microscopy. Stratum corneum lipid content was reduced in IUGR pups relative to surface area ( $\mu \mathrm{g}$ lipid/ $\mathrm{cm}^{2}$ ) but was preserved relative to its structural protein content ( $\mu \mathrm{g}$ lipid/mg dry weight). Thus, IUGR in the fetal rat does not delay development of a competent barrier or maturation of the barrier membrane system. (Pediatr Res 33: 418-424, 1993)
\end{abstract}

\section{Abbreviations}

GA, gestational age

TEWL, transepidermal water loss

IUGR, intrauterine growth retardation

TLC, thin-layer chromatography

In terrestrial mammals, the permeability barrier resides in the stratum corneum (reviewed in 1,2). This tissue has been likened

Received August 17, 1992; accepted December 17, 1992

Correspondence and reprint requests: Mary L. Williams, M.D., Dermatology Service (190), V.A. Medical Center, 4150 Clement St., San Francisco, CA 94121.

Supported in part by NIH Grants AR29908R and AR39639 and the Medica Research Service of the Department of Veterans Affairs. to a brick wall in which anucleate corneocytes (the bricks) are filled with keratin filaments and enclosed by a highly cross-linked protein envelope. The corneocytes are surrounded by a matrix (the mortar), composed of multiple membrane bilayers that are enriched in cholesterol, ceramides, and FFA. Precursors of these lipids are delivered to the intercellular locale by a secretory organelle, the epidermal lamellar body $(3,4)$. After secretion, lamellar body lipids are modified by hydrolytic enzymes $(3,4)$ and reorganized to form a repeating pattern of electron-lucent and electron-dense lamellae, termed the basic lamellar unit structure $(2,5,6)$

In man, the cutaneous permeability barrier forms during late gestation such that preterm infants less than 33 wk of GA exhibit increased TEWL and increased percutaneous absorption of topically applied compounds (7-10). Although barrier immaturity is a significant source of morbidity and mortality in the very premature infant (11-13); little is known about barrier maturation. The fetal rat may provide a convenient model for the study of barrier ontogenesis (16). In this species (16), as in man (7-10) and swine (17), a competent barrier is established during late gestation. Moreover, as in mature animals (2), establishment of a competent barrier in the fetal rat is accompanied by the accumulation of nonpolar lipid, particularly cholesterol and ceramides, in the form of lamellar unit structures throughout the intercellular domains of stratum corneum (16).

In small-for-dates infants, barrier function is generally appropriate for GA (18). Yet, many of the clinical signs of the runted infant involve the skin, including decreased subcutaneous fat, decreased vernix caseosa, and dry scaly skin (19). Moreover, epidermal and stratum corneum thickness are reduced in smallfor-dates infants (20) and in fetal rats subjected to IUGR through either dietary protein restriction (20) or unilateral uterine vessel ligation $(21,22)$. Furthermore, the content of the differentiationspecific epidermal proteins, keratins and profilaggrin, is reduced in IUGR fetal rats (22). This implies that epidermal differentiation is impaired under the stress of IUGR in this model (22). Therefore, we undertook these studies to determine whether IUGR also impairs maturation of the permeability barrier in the fetal rat.

\section{MATERIALS AND METHODS}

Materials. Ruthenium tetroxide and nile red were obtained from Polysciences, Inc. (Warrington, PA) and OCT compound was obtained from Miles Scientific (Naperville, IL). Authentic lipid standards were purchased from Sigma Chemical Co. (St. Louis, MO) and Avanti Polar Lipids, Inc. (Pelham, AL). The "acylceramide" standard, BRS-001 \{[N-( $\omega$-linoleoyloxy)-palmitoyl]-N-[3-(cetyl-ether)-isopropanyl]-ethanolamine\}, was a generous gift of Dr. Genji Imokawa, Kao Corporation (Tochigi, Japan). High performance silica gel TLC plates were purchased from Merck (Darmstadt, Germany). 


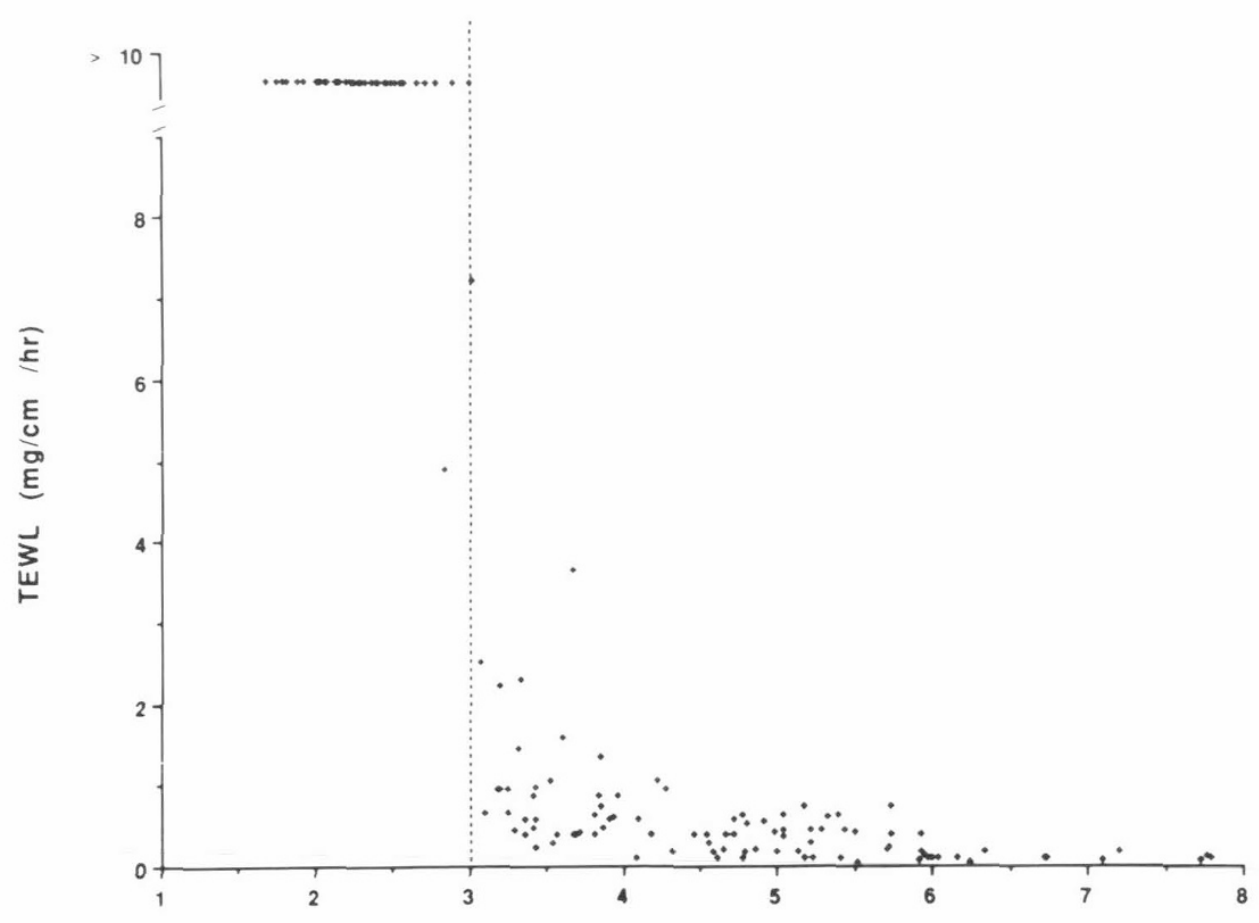

Weight (g)

Fig. 1. Relationship between body weight and barrier function during normal ontogenesis in the fetal rat. Fetal rats between 19 and 22 (term) $\mathrm{d}$ GA were obtained by cesarean section. TEWL was measured and pups were then weighed. Note that most pups weighing $<3 \mathrm{~g}$ have no measurable barrier (TEWL $>10 \mathrm{mg} / \mathrm{cm}^{2} / \mathrm{h}$ ), whereas pups weighing $>4.5 \mathrm{~g}$ exhibit competent barriers.

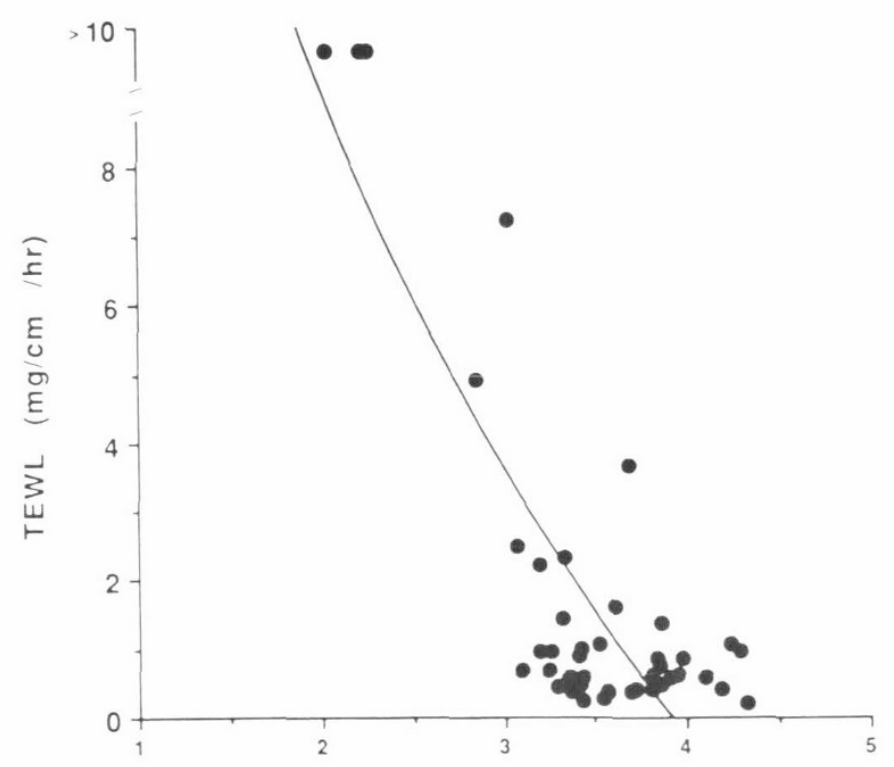

Weight (g)

Fig. 2. Relationship between body weight and barrier function in fetal rats on d 20 of gestation. A measurable barrier to TEWL first appears on 20 of gestation in the fetal rat (16). Even in rats of this age. barrier competence is correlated with increasing fetal weight $(r=$ $-0.7945: p<0.001$ ).

Tissue preparation. Timed-pregnant (plug date $=\mathrm{d} 0$ ) primiparous Sprague-Dawley rats $(6-10 \mathrm{wk})$ were obtained from Simonsen Laboratories (Gilroy, CA) and fed Purina Laboratory Chow 5001 (Ralston-Purina Co., St. Louis, MO) and water ad libitum. On d 17 or 18 of gestation, the uterus of some pregnant rats was exteriorized through a midline abdominal incision and the uterine vessels unilaterally ligated, as described previously $(21,22)$. Pups were harvested by cesarean section on d 20, 21 , or 22, and TEWL was measured from the interscapular region by using the MEECO electrolytic moisture analyzer (MEECO, Warrington, PA) $(16,23)$. Data are expressed as $\mathrm{mg} \mathrm{H}_{2} \mathrm{O} / \mathrm{cm}^{2} / \mathrm{h}$ (mean \pm SEM) (24). For statistical purposes, off-scale readings (i.e. TEWL $>10 \mathrm{mg} / \mathrm{cm}^{2} / \mathrm{h}$ ) were recorded as $10 \mathrm{mg} / \mathrm{cm}^{2} / \mathrm{h}$. Data from IUGR pups was compared with those from littermates from the unligated uterine horn (control) by using the two-tailed $t$ test. Pups were weighed and killed, and epidermal-dermal and stratum corneum separations were obtained as described previously (16).

TLC. Lipids were extracted from the stratum corneum sheets, weighed, and fractionated by high-performance TLC followed by charring and scanning densitometry (16, 25). For quantitation of ceramides, $8 \mu \mathrm{g}$ of each fetal lipid sample was applied in a $0.5-\mathrm{cm}$ lane. Plates were developed twice in chloroform:methanol:acetic acid $(95: 4: 1, \mathrm{vol} / \mathrm{vol})$ to the top, and ceramide fractions were quantitated in reference to the closest migrating ceramide standard.

Light and electron microscopy: For enumeration of stratum corneum cell layers, alkaline expansions of stratum corneum sheets were performed as described previously (26). The average number of stratum corneum layers was determined by direct counting using a dissecting microscope. An average of 10 separate areas were counted on each specimen to arrive at the final number of layers. The overall average for each pup was then used for statistical comparison to avoid problems of inclusion of multiple samples from individual animals. Full-thickness skin for light microscopy was frozen at $70^{\circ} \mathrm{C}$, then embedded in OCT compound and sectioned, and nile red $(100 \mu \mathrm{g} / \mathrm{mL}, 75 \%$ glycerol) was applied (27). Sections were examined with a Nikon Microphot-FX microscope equipped with epifluorescence (exci- 
tation of 470-490 nm, emission $520 \mathrm{~nm}$ ). Full-thickness skin was minced to 1-mm fragments, fixed in modified Karnovskey's fixative, and processed for electron microscopy (28). Sections were double-stained with uranyl acetate and lead citrate or lead citrate alone as previously described (16) and examined using a Zeiss $10 \mathrm{~A}$ electron microscope at $60 \mathrm{kV}$.

\section{RESULTS}

Barrier function versus fetal size. To determine the relationship between fetal size and barrier competence during normal fetal rat ontogenesis, TEWL was determined in pups of between 19 and $22 \mathrm{~d}$ GA $(22 \mathrm{~d}=$ term $)$ and plotted against fetal body weight (Fig. 1). Barrier competence was correlated with increasing fetal size; whereas for the most part pups weighing less than $3 \mathrm{~g}$ exhibited no measurable barrier to water loss, pups weighing greater than 4.5 g exhibited competent barriers (Fig. 1). We have previusly demonstrated that GA is also a critical determinant of barrier competence in the fetal rat, such that pups of $19 \mathrm{~d} \mathrm{GA}$ or less exhibit no measurable barrier to TEWL. whereas pups of 21 d GA or greater exhibit competent barriers. Because a measurable TEWL barrier first emerges on d 20 of gestation during normal ontogenesis (16), we therefore assessed the relationship between barrier competence and fetal size within this age group. As shown in Figure 2, among pups of $20 \mathrm{~d} \mathrm{GA}$, barrier function also correlated with fetal size $(r=-0.7945 ; p<0.001)$. Four pups having the highest TEWL (no measurable barrier) were all derived from a single litter. This raises the possibility that variation in hours of age within the d-20 GA group could account for some of the variability in TEWL that we observed. Although we performed all experiments at the same time of day, we cannot exclude possible variations by our animal vendors in the time of matings. However, the other nine litters exhibited a considerable spread in TEWL measurements among littermates, suggesting that small differences in GA cannot account for the major portion of the variations in TEWL within this age group.

To explore the relationship between fetal size and barrier competence further, fetal rats were subjected to IUGR by unilateral ligation of the uterine vessels (Wigglesworth procedure) on the 17 th or 18 th $d$ of gestation $(21,22)$. As shown in Table 1 ,

Table 1. Body weight and stratum corneum lipid content in IUGR vs control littermates*

\begin{tabular}{|c|c|c|c|c|}
\hline \multirow[b]{2}{*}{ Litter } & \multirow{2}{*}{$\begin{array}{c}\text { No. IUGR } \\
\text { pups/no. } \\
\text { control pups }\end{array}$} & \multirow{2}{*}{$\begin{array}{l}\text { Body weight } \\
\text { (\% change) }\end{array}$} & \multicolumn{2}{|c|}{$\begin{array}{c}\text { SC lipid content } \\
{[\% \text { change (IUGR/control)] }}\end{array}$} \\
\hline & & & $\mu \mathrm{g}$ lipid $/ \mathrm{cm}^{2}$ & $\mu \mathrm{g} \mathrm{lipid} / \mathrm{mg} \mathrm{SC}$ \\
\hline \multicolumn{5}{|l|}{ GA d 21} \\
\hline 1 & $5 / 4$ & $-23 \dagger$ & -6 & ND \\
\hline 2 & $6 / 8$ & $-27 \ddagger$ & $-25 \S$ & ND \\
\hline \multicolumn{5}{|l|}{ GA d 22} \\
\hline 3 & $3 / 5$ & $-24 \dagger$ & $-25 \dagger$ & ND \\
\hline 4 & $3 / 4$ & $-36 \ddagger$ & -3 & 30 \\
\hline 5 & $4 / 4$ & $-37 \ddagger$ & -21 & 52 \\
\hline 6 & $3 / 4$ & $-43 \ddagger$ & -20 & 27 \\
\hline 7 & $3 / 4$ & $-33 \ddagger$ & -21 & $74 \ddagger$ \\
\hline Total & & ND & -17 & $44 \ddagger$ \\
\hline
\end{tabular}

* IUGR was produced during late gestation by unilateral uterine artery ligation $(21,22)$. At 21 or 22 (term) d GA, IUGR pups from the ligated uterine horn and control littermates from the unligated uterine horn were obtained by cesarean section and weighed. Stratum corneum sheets were isolated and lipids extracted and weighed. Data were normalized to surface area $\left(\mathrm{cm}^{2}\right)$ or to stratum corneum dry weight $(\mathrm{g})$ and are expressed as the \% change IUGR/control. SC, stratum corneum; ND, not determined.

$$
\begin{aligned}
& \dagger p<0.02 . \\
& \ddagger p<0.01 . \\
& \S p<0.05 .
\end{aligned}
$$

pups from the ligated uterine horn (IUGR) were significantly smaller than their unligated littermates (control) at both 21 and $22 \mathrm{~d}$ GA. Figure 3 illustrates the relationship between body weight and TEWL in IUGR versus control pups between 20 and $22 \mathrm{~d}$ GA. Note that several IUGR pups weighed less than $3 \mathrm{~g}$ but still exhibited measurable barriers (Fig. 3), whereas during normal gestation pups of this size rarely do (Fig. 1). Figure 4 compares barrier function in IUGR and control littermates in relation to GA. The apparent difference in barrier function between IUGR and control littermates at $20 \mathrm{~d}$ did not achieve statistical significance due to the wide range in barrier competence at this age (Fig. 2). Clearly, barrier function was equally

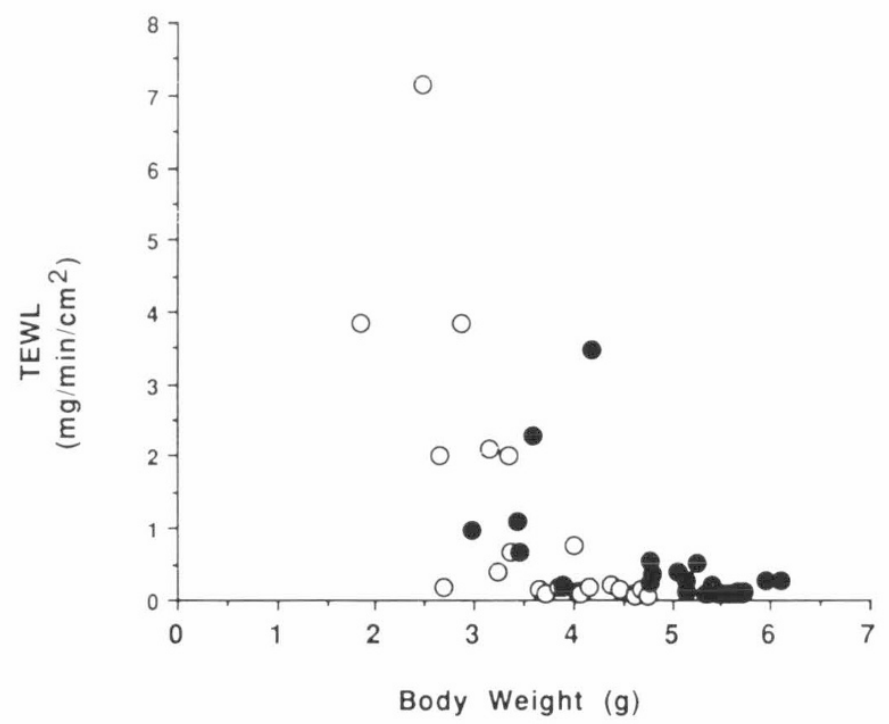

Fig. 3. Relationship between body weight and barrier function in IUGR and control littermates. IUGR fetal rats were prepared by unilateral intrauterine vessel ligation $(21,22)$ and pups were obtained from the unligated (control; ) and ligated (IUGR; O) rats on d 20, 21, or 22 of gestation for determination of TEWL. Although several IUGR pups weighed $<3 \mathrm{~g}$ (the threshold weight for a measurable barrier during normal gestation), all exhibited measurable barriers.

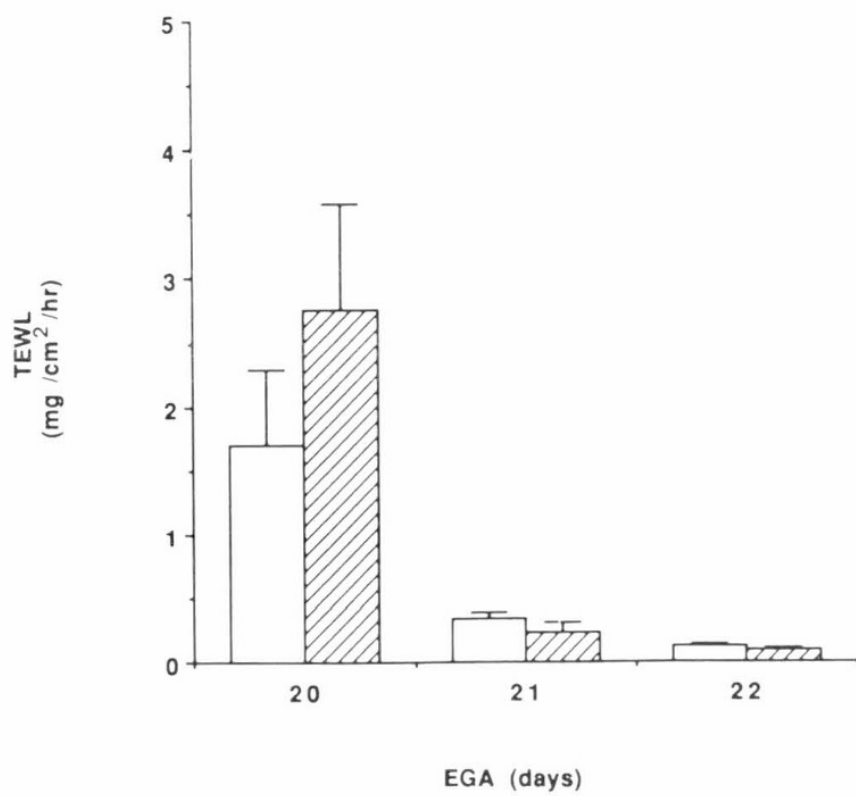

Fig. 4. Comparison of barrier function in control ( $\square$ ) vs IUGR (שי ) fetal rats in relation to GA. No significant difference in TEWL between IUGR and control littermates was observed at any age. 

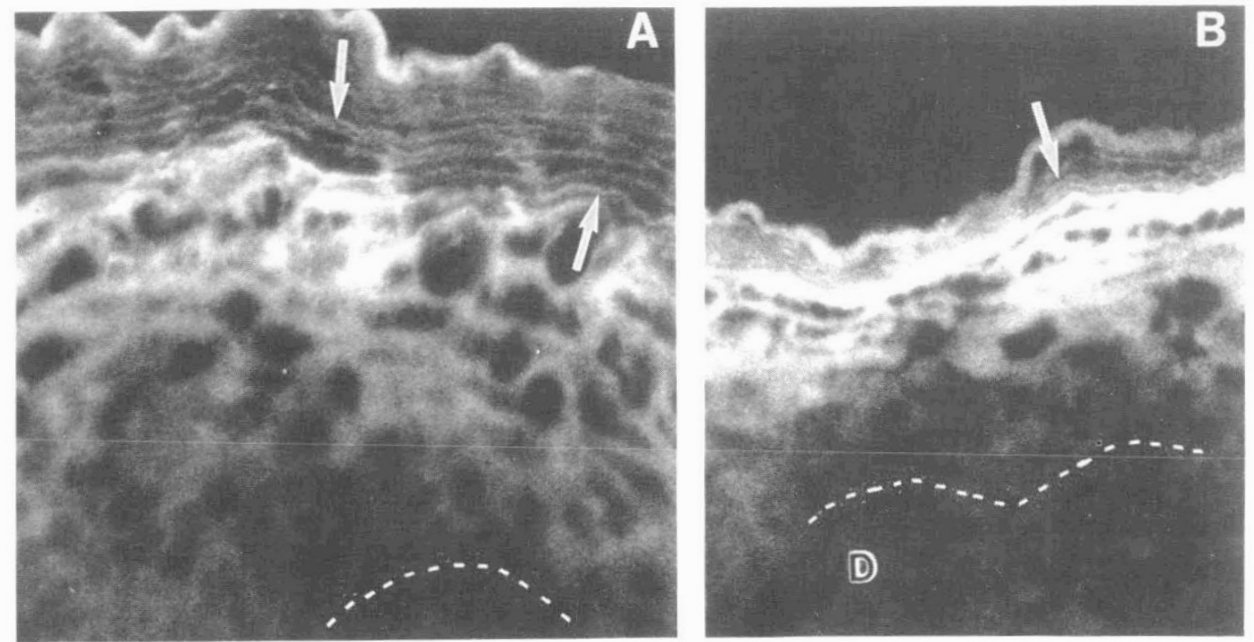

Fig. 5. Nile red fluorescence histochemistry of control $(A) v_{S} \operatorname{IUGR}(B)$ fetal rat skin at $21 \mathrm{~d}$. The epidermis and stratum corneum are thicker in the control pup than in an IUGR littermate. Note that both control and IUGR stratum corneum exhibits a peripheral membrane pattern (arrows) of nile red fluorescence, which is indicative of neutral lipid deposition in the intercellular domains. The dotted lines indicate the approximate region of the dermal-epidermal junction. $D$, dermis.

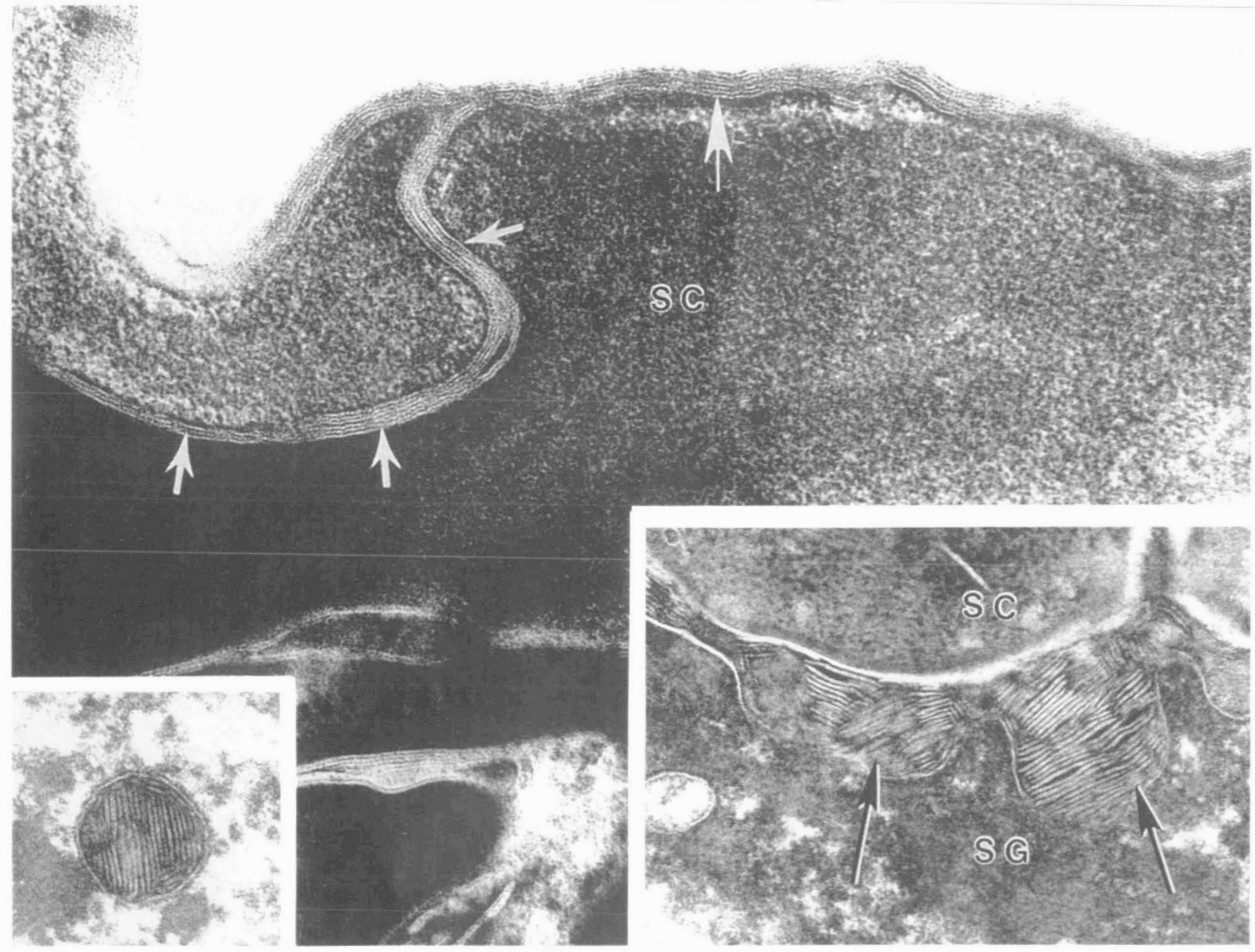

Fig. 6. Electron micrograph of control (21 d GA) outer epidermis. Lamellar bilayer unit structures (white arrows) fill the intercellular domains of the stratum corneum (SC) (ruthenium tetroxide; $80000 \times$ ). Left inset. In epidermis, lamellar bodies exhibit a mature lamellar substructure $(125000 \times)$. Right inset, Secreted lamellar body contents fill the stratum granulosum $(S G)$-stratum corneum $(S C)$ interface $(126000 \times)$.

competent in IUGR and control pups at both 21 and $22 \mathrm{~d}$ (Fig. $3)$. These studies therefore demonstrate that, although barrier competence is correlated with increasing body weight during normal ontogenesis. IUGR does not significantly retard establishment of a competent barrier in the fetal rat.
Light microscopv. In the mature animal, neutral lipid is deposited in a peripheral membrane pattern in the stratum corneum as revealed by hydrophobic probes such as nile red $(28$, 29). Similarly, in the fetal rat, development of a competent barrier is correlated with increasing stratum corneum thickness 
and with the deposition of neutral lipid in a peripheral membrane pattern (16). Figure 5 compares the light microscopic features of IUGR fetal rat epidermis with those of controls at $21 \mathrm{~d} \mathrm{GA}$ by nile red fluorescence microscopy. As reported previously $(18,19$.
21). epidermis of IUGR fetal rats is thinner in comparison to control littermates. The apparent decrease in thickness of stratum corneum was quantitated using alkaline expansion to permit direct counting of corneum layers (26). At 21 d, IUGR rat pups
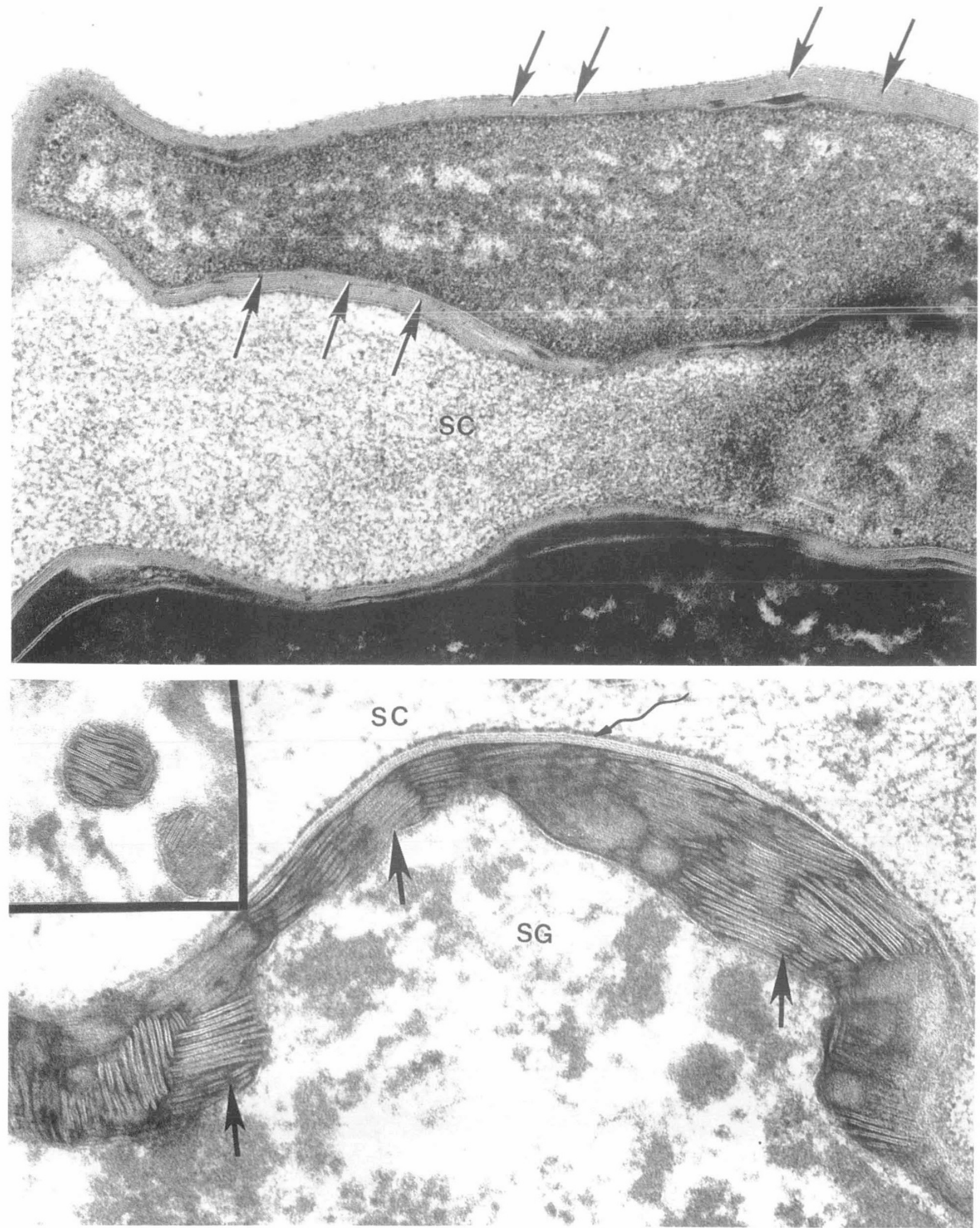

Fig. 7. Electron micrograph of IUGR (21 d GA) outer epidermis. Upper panel, As in control littermates (Fig. 6), lamellar bilayer unit structures (arrows) fill the intercellular domains throughout the stratum corneum (SC) (ruthenium tetroxide: $75000 \times$ ). Inset. Lamellar bodies exhibit a mature lamellar substructure $(100000 \times)$. Lower panel, Secreted lamellar body contents (arrows) fill the intercellular domain at the stratum granulosum $(S G)$-stratum corneum $(S C)$ interface. Reorganization into lamellar unit structures (wavy arrow) is evident in some regions ( $125000 \times$ ). 
exhibited $6 \pm 0.3$ (mean $\pm \mathrm{SE}, n=3$ ) layers of stratum corneum, compared with $9 \pm 0.3(n=3)$ cell layers in control littermates $(p<0.05)$. Yet, despite the reduced thickness of IUGR stratum corneum, it retains the mature, peripheral membrane-pattern of yellow-orange nile red fluorescence (Fig. 5). These data imply that, although epidermis in IUGR rat pups is growth-retarded, differentiation to form a mature membrane pattern of lipid deposition in stratum corneum is not impeded.

Electron microscopy. To further assess differentiation of the stratum corneum membranes, we examined ruthenium-tetroxide-stained ultrathin sections of control and IUGR epidermis (Figs. 6 and 7, respectively). Despite the thinner stratum corneum of IUGR fetal rats, a mature lamellar body secretory system was present (Fig. 7). Lamellar bodies exhibited the expected lamellar substructure (Fig. 7, inset) for pups of this GA (Fig. 6, left inset). Moreover, after secretion into the intercellular domain at the stratum granulosum-stratum corneum interface (Fig. 7, top), lamellar body contents were reorganized to form mature lamellar unit structures (Fig. 7, bottom). Furthermore, as expected for this age, lamellar unit structures filled the intercellular domains throughout the stratum corneum (Fig. 7, top). Thus, no differences in the ultrastructure of the lamellar body secretory system were evident between IUGR (Fig. 7) and control (Fig. 6) fetai rats. Despite a decrease in overall tissue thickness, the expected maturation in stratum corneum membrane ultrastructure was preserved in the IUGR fetal rat.

Lipid biochemistry. Development of a competent barrier during normal ontogenesis is correlated with increasing stratum corneum lipid content (16). Therefore, we next determined the lipid content of isolated stratum corneum sheets from IUGR and control littermates at 21 and $22 \mathrm{~d}$ GA. Data were normalized either to stratum corneum surface area ( $\mu \mathrm{g}$ lipid $\left./ \mathrm{cm}^{2}\right)$ or dry weight ( $\mu \mathrm{g}$ lipid $/ \mathrm{mg}$ stratum corneum) (Table 1). Whereas the former are more directly correlated with TEWL measurements, which are also expressed in reference to surface area, the latter permits assessment of lipid content relative to its structural protein content. When normalized to surface area, the lipid content of stratum corneum from IUGR littermates was consistently less than that from control littermates, although these differences achieved statistical significance in only a few litters, due in part to the inherent limitation of sample size within litters. Yet, even when data from all litters were pooled, no significant differences in IUGR versus control stratum corneum lipid content relative to surface area were observed (Table 1). However, the opposite trend was observed when the data were expressed relative to stratum corneum dry weight: $i$.e. the lipid content of IUGR stratum corneum was consistently increased when compared with that of control littermates (Table 1). Moreover, this increase remained highly significant when data from all litters were pooled.

To examine the effect of IUGR on the content of specific lipid fractions in the stratum corneum, lipids were fractionated and quantitated by high-performance TLC-scanning densitometry (Table 2). Data were normalized to stratum corneum surface area. The cholesterol and total ceramide content of IUGR epidermis was consistently reduced, and in several litters these differences were significant. Seven ceramide fractions were present in quantifiable amounts and designated in order of increasing polarity (decreasing $\mathrm{R}_{\mathrm{f}}$ ). Whereas the content of the most nonpolar fraction (ceramide 1), the ceramide fraction migrating closest to our acylceramide standard, and of the two most polar (ceramides 6 and 7) ceramide fractions was relatively spared, the content of ceramides of intermediate polarity (fractions 2-5) were significantly decreased in IUGR pups in two litters (Table 2).

\section{DISCUSSION}

These studies demonstrate that although barrier maturation is correlated with fetal size during normal ontogenesis, somatic
Table 2. Stratum corneum lipid fractions in IUGR vs control littermates*

Stratum corneum lipid content (\% change) $21 \mathrm{~d}$ $22 \mathrm{~d}$

\begin{tabular}{lccccc}
\cline { 2 - 3 } \cline { 5 - 6 }$\quad$ Lipid fraction & Litter 1 & Litter 2 & Litter 3 & Litter 4 & Litter 5 \\
Cholesterol & $-35 \dagger$ & $-31 \ddagger$ & $-38 \S$ & -17 & $-37 \dagger$ \\
Total ceramides & -14 & -20 & $-29 \S$ & -18 & $-40 \S$ \\
Ceramide fractions & & & & & \\
1 & 7 & 129 & -15 & & \\
2 & -23 & -28 & $-33 \S$ & & \\
3 & -26 & $-32 \dagger$ & $-30 \S$ & & \\
4 & -8 & $-22 \dagger$ & $-31 \ddagger$ & & \\
5 & -6 & $-41 \S$ & $-39 \S$ & & \\
6 & -5 & -3 & 9 & & \\
7 & -7 & -3 & -18 & &
\end{tabular}

* Lipids were fractionated and quantitated by high performance TLC/ scanning densitometry (8). Ceramide fractions are designated in order of increasing polarity. Data are expressed as \% change, mean $\mu \mathrm{g}$ lipid fraction $/ \mathrm{cm}^{2}$, IUGR/control.

$$
\begin{aligned}
& +p<0.05 . \\
& \ddagger p<0.02 . \\
& \S p<0.01 .
\end{aligned}
$$

growth retardation does not disrupt the timetable for establishment of a competent barrier in the fetal rat (Figs. 1-4). Indeed, barrier maturation proceeds despite obvious growth retardation of the epidermis and overlying stratum corneum (Fig. 5). Thus. these data suggest that the processes that underlie maturation of the barrier are tightly regulated during ontogenesis.

In mature skin, the permeability barrier is provided by a mixture of relatively hydrophobic lipids, enriched in cholesterol, ceramides, and FFA, which form multiple membrane bilayers in the intercellular domains of the stratum corneum $(1,2)$. Similarly, we have shown that development of barrier competence in the fetal rat parallels the appearance of basic lamellar unit structures throughout the stratum corneum interstices and the further enrichment of stratum corneum lipids by cholesterol and nonpolar ceramides (16). In the IUGR fetal rat, formation of basic lamellar unit structures occurs at the expected time in gestation (Fig. 7), despite marked growth retardation of the ep dermis, including a thinner stratum corneum. Using the same IUGR model. Hoath et al. (22) also demonstrated significant retardation in the accumulation of the epidermal structural proteins, keratins and profilaggrin. We also observed a trend toward decreased lipid accumulation in IUGR versus control stratum corneum ( $\mu \mathrm{g}$ lipid $\left./ \mathrm{cm}^{2}\right)$, although in most litters and in aggregate these differences did not achieve statistical significance (Table 1). Moreover, when the content of specific barrier lipids was assessed, we did observe a significant decrease in the cholesterol and ceramide content $\left(\mu \mathrm{g}\right.$ lipid $\left./ \mathrm{cm}^{2}\right)$ of IUGR stratum corneum in several litters. The tendency toward decreased lipid content/surface area in IUGR stratum corneum is not surprising in view of the considerable decrease in overall thickness of IUGR stratum corneum. Yet, when the data were expressed in relation to stratum corneum dry weight ( $\mu \mathrm{g}$ lipid/mg stratum corneum), the lipid content of IUGR stratum corneum was increased. This indicates a relative sparing of lipid accumulation in comparison to structural protein content under the stress of placental insufficiency.

Immaturity of the skin barrier in the preterm infant is the source of significant morbidity and mortality (11-13). Yet despite its clinical importance, the study of barrier ontogenesis has been remarkably neglected. An essential first step in redressing this neglect lies in the development of a suitable animal model. In addition to its small size and relatively low cost, the fetal rat offers the advantage of a hairless state during uterine life and in the first postnatal days, a feature that greatly facilitates study of 
permeability barrier function, as well as preparation of tissues for lipid analysis free of pilosebaceous contributions. Moreover, it is important that the animal model selected mimic the human situation. We believe, therefore, that our demonstration that barrier ontogenesis is preserved in IUGR fetal rat, as it is in man (6), provides further validation of this model system. Additionally, this model offers potential for the exploration of factors that regulate epidermal barrier maturation. Indeed, we have recently demonstrated that glucocorticoids accelerate maturation of the permeability barrier and the epidermal lamellar body secretory system in the fetal rat (30).

Acknowledgments. The authors thank Joanne Buehler and Robin Steirwalt for their able technical assistance and Sally Michael and Bil Chapman for manuscript preparation.

\section{REFERENCES}

1. Elias PM 1983 Epidermal lipids, barrier function, and desquamation. J Invest Dermatol 80:44-49

2. Elias PM, Menon GK 1991 Structural and lipid biochemical correlates of the epidermal permeability barrier. Adv Lipid Res 24:1-26

3. Grayson S, Johnson-Winegar AG, Wintroub BU, Epstein Jr EH, Elias PM 1985 Lamellar body-enriched fractions from neonatal mice: preparative techniques and partial characterization. J Invest Dermatol 85:289-295

4. Freinkel RF, Traczyk TN 1985 Lipid composition and hydrolase content of lamellar granules of fetal rat epidermis. J Invest Dermatol 85:295-298

5. Madison KC, Swartzendruber DC, Wertz PW, Downing DT 1987 Presence of intact intercellular lipid lamellae in the upper layers of the stratum corneum. J Invest Dermatol 88:714-718

6. Hou SYE, Mitra AK, White SH, Menon GK, Ghadially R, Elias PM 1991 Membrane structures in normal and essential fatty acid deficient stratum corneum: characterization by ruthenium tetroxide staining and $x$-ray diffraction. J Invest Dermatol 96:215-223

7. Rutter N, Hull D 1979 Water loss from the skin of term and preterm babies. Arch Dis Child 54:858-868

8. Nachman RL, Esterly NB 1971 Increased skin permeability in preterm infants. J Pediatr 79:628-632

9. Wilson DR, Maibach HI 1980 Transepidermal water loss in vivo preterm and term infants. Biol Neonate 37:180-185

10. Hammarlund K, Sedin G 1979 Transepidermal water loss in newborn infants. III. Relation to gestational age. Acta Paediatr Scand 68:795-801

11. Maurer A, Micheli JL, Schutz Y, Freymond D, Jequir E 1984 Transepidermal water loss and resting energy expenditure in preterm infants. Helv Paediatr Acta 39:405-418
12. Hammarlund K, Stromberg B, Sedin G 1986 Heat loss from the skin of preterm and fullterm newborn infants during the first weeks after birth. Biol Neonate 50:1-10

13. Vernon HJ, Lane AT, Wischerath LJ, Davis JM, Menegus MA 1990 Semipermeable dressing and transepidermal water loss in premature infants. Pediatrics 86:357-362

14. Deleted in proof

15. Deleted in proof

16. Aszterbaum M, Feingold KR, Menon GK, Williams ML 1992 Ontogeny of the epidermal barrier to water loss in the rat: correlation of function with stratum corneum structure and lipid content. Pediatr Res 31:308-317

17. Kurihara-Bergstron T, Good WR, Signor C, Woodwruth M 1990 Epidermal differentiation and permeability in fetal pig skin. Pharmacol Res 7:12011204

18. Hammarlund K, Seden G 1980 Transepidermal water loss in newborn infants. IV. Small for gestational age infants. Acta Paediatr Scand 69:377-383

19. Kliegmann RM, Hulman SE 1987 Intrauterine growth retardation: determinants of aberrant fetal growth. In: Faranoff AA, Martin RJ (eds) Neonatal Perinatal Medicine, 4th Ed. CV Mosby Co, St. Louis, pp 43-94

20. Lansdown ABG 1978 Epidermal differentiation in normal and growth-retarded infants: studies in two animal models and in human babies. $\mathrm{Br} \mathrm{J}$ Dermatol 99:139-146

21. Wigglesworth JS 1964 Experimental growth retardation in the foetal rat. J Pathol Bacteriol 88:1-13

22. Hoath SB, Pickens WL, Sells SF, Boissy RE 1990 Epidermal development in the growth retarded fetal rat. J Dev Physiol 13:41-50

23. Menon GK. Feingold KR, Moser AH, Brown BE, Elias PM 1985 De novo sterologenesis in the skin. II. Regulation by cutaneous barrier requirements. J Lipid Res 26:418-427

24. Feingold KR, Mao-Qiang M, Proksch E, Menon GK. Brown B, Elias PM 199! The lovastatin-treated rodent: a new model of barrier disruption and epidermal hyperplasia. J Invest Dermatol 96:201-209

25. Ponec M, Weerheim A, Kempenaar J, Mommaas AM, Nugteren DH 1988 Lipid composition of cultured human keratinocytes in relation to their differentiation. J Lipid Res 29:949-961

26. MacKenzie IC, Zimmerman K 1981 The development of ordered structure in neonatal rat epidermis. J Invest Dermatol 77:278-282

27. Fowler SD, Greenspan PH 1985 Application of nile red, a fluorescent hydrophobic probe, for the detection of neutral lipid deposits in tissue sections. J Histochem Cytochem 33:833-836

28. Elias PM, Brown BE, Fritsch PO, Goerke RJ, Gray GM, White RJ 1979 Localization and composition of lipids in neonatal mouse stratum granulosum and stratum corneum. J Invest Dermatol 73:339-348

29. Grubauer G, Feingold KR, Harris RM, Elias PM 1989 Lipid content and lipid type as determinants of the epidermal permeability barrier. J Lipid Res 30:89-96

30. Aszterbaum M, Feingold KR, Menon GK, Buehler J, Williams ML 1992 Glucocorticoids accelerate maturation of the permeability barrier. Clin Res 40:309A(abstr) 